\title{
As Comissões Permanentes e Temporárias do Poder Legislativo e suas atribuições
}

Chagas Melo

A

S comissões do legislativo são de duas naturezas: I - as permanentes que permanecem através das legislaturas e II as temporárias que se extinguem com a terminação da legislatura ou antes dela, quando preenchido o fim a que se destinam.

Organizadas com base na proporcionalidade da representação partidária, as comissões permanentes ou técnicas têm por fim principal estudar os assuntos submetidos regimentalmente, ao seu exame e sôbre êles manifestar a sua opinião.

$\mathrm{O}$ número das comissões permanentes varia com o tamanho da casa legislativa. $\mathrm{Na}$ Câmara Federal temos as seguintes comissões permanentes: de Constituição e Justiça, de Economia, Educação e Cultura, Finanças, Legislação Social, Orçamento, Fiscalização e Tomada de Contas, Minas e Energia, Agricultura e Produção Agrícola, Redação, Relações Exteriores, Saúde, Segurança Nacional, Serviço Público e Transporte, Comunicações, e Obras Públicas.

Nas Assembléias legislativas dos grandes Estados como São Paulo, Minas, Rio Grande do Sul, Bahia e Pernambuco, as comissões permanentes podem ser em número de oito assim denominadas: Constituição e Justiça, Agricultura, Indústria e Comércio, Viação e Obras Públicas, Orçamento e Finanças, Educação e Assistência Social, Serviço Público e de Redação.

Nos Estados menores as comissões podem ser reduzidas e grupadas na seguinte base: Constituição e Justiça, Orçamento e Finanças, Educação, Saúde e Assistência Social, Viação, Agricultura, Indústria e Comércio e Administração e Redação.

Nas Câmaras de Vereadores das capitais podemos aplicar o esquema dos Estados menores e nas demais Câmaras dos Vereadores o seguinte: Constituição e Justiça, Viação e Agricultura, Orçamento e Finanças, Educação, Saúde e Assistência Social.

A mais importante comissão é certamente a de Constituição e Justiça que estuda as proposições em geral sob o aspecto constitucional, jurídico e de técnica legislativa interrompendo a tramitação das mesmas se elas forem julgadas inconstitucionais até que 
o plenário se manifeste em definitivo. É o que regimentalmente chamamos de discussão prévia.

As atribuições das demais comissões estão expressas nos regimentos das casas legislativas, não podendo uma comissão invadir a competência privativa da outra.

As comissões permanentes ou técnicas das casas legislativas no Brasil ainda conservam uma estrutura antiga, sem atribuições importantes, sendo os seus pareceres mutilados ou derrotados no plenário, desfigurando-se as proposições que passam a refletir o resultado de combinações políticas transitórias, prejudicando o aspecto técnico que deve predominar na elaboração das leis.

A reestruração das comissões permanentes com o fortalecimento de suas atribuições pela delegação de podêres dos vários partidos aos representantes que as integram repousa em duas modificações importantes; a) aos projetos do Executivo só serão oferecidas emendas nas comissões, sendo final o seu pronunciamento, salvo se a maioria da casa legislativa solicitar ao respectivo Presidente a votação no plenário, sem discussão, da emenda aprovada ou rejeitada; b) delegação de competência, por um têrço da totalidade dos membros de uma casa legislativa, às comissões especializadas para elaborarem projetos definitivos de lei, à exceção dos que versem sôbre matéria eleitoral, orçamenária, minas, quedas de água ou ratificações de tratados. Publicado o projeto, dentro de cinco dias, um quarto da casa legislativa poderá solicitar ao respectivo Presidente que o projeto da Comissão seja submetido à deliberação do plenário, que, entretanto, não poderá emendá-lo, aceitando-o ou rejeitando-o.

«Les Parlaments ont tous plus de travail qu'ils n'en peuvent expédier, car la complexité des Êtats modernes et l'intervention de la puissance publique, notamment dans la vie économique, grandissent chaque jour. Le problème, dans tous les pays, consiste à aménager le temps du Parlement par un ordre du jour bien étudié et par la réductien de la longueur des débats.

«Em Italie, la Constitution permet le vote définitif des lois d'intérêt secondaire par les Commissions elles-mêmes, sous réserve du renvei devant l'Assemblée plénière à la demande d'un certain nombre de députés. En Angleterre, par la procédure dénommée «guillotine» un débat em clos à une heure determinée, qual que soit le point òu il est arrivé et la Chambre vote. - Emile Blamont - Les Techniques Parlamentaires - Presses Universitaires de France - 1958 - página 39.

As casas legislativas devem separar muito bem duas etapas importantes em seus trabalhos: a elaboração legislativa principal nas comissões técnicas e o debate politico no plenário que aprova ou rejeita o trabalho técnico das comissões.

«Na Itália, quando funcionam com podêres legislativos, para deliberar em definitivo pela Câmara, as Comissões se reúnem com 
a participação dos Ministros. Ouvido o relator designado pelo Presidente, procede-se à discussão e a votação do projeto. Das reuniões se fazem duas atas - uma sintética e uma por extenso, constante do registro estenográfico. Qualquer Deputado pode tomar parte no debate que se travar, mesmo que não pertença à Comissão, mas sem voto. Se o projeto tem disposições que aumentem despesa ou reduzem receita, é necessário o pronunciamento da Comissão de Finanças, por escrito. Se a Comissão encarregada do estudo da matéria não concordar com o pronunciamento da de Finanças e esta nêle insistir, o Presidente da Câmara decide se as duas devem reunir-se em conjunto para deliberar em definitivo, ou se o caso deve ser afets ao plenário. Nas reuniões das Comissões, para requerer votação nominal ou verificação de votação são necessários quatro Deputados; para escrutínio secreto cinco. Terminado, com a aprovação final, o estudo do projeto distrịbuído a uma Comissão para sôbre êle deliberar em definitivo, o Presidente da Câmara dá conhecimento ao Plenário desta, da aprovação. Até o momento da votação definitiva na Comissão, é lícito ao Govêrno requerer seja o projeto submetido ao Plenário da Câmara. Igual faculdade é prevista para um décimo dos Deputados e para um quinto dos membros da Comissão.

Não podem ser enviados às Comissões para deliberação em definitivo projetos que tratem de matéria constitucional, aprovem despesas ou tratem de matéria tributária ou orçamentária e ratifiquem tratados internacionais» página 279. «Algumas Casas de Parlamento da Europa» - Senador Marcondes Filho - Revista do Serviço Público - nov - dez de 1957.

As comissões permanentes dão início ao exame de qualquer proposição sujeita ao exame da Casa Legislativa, sendo de competência do Presidente da mesma Casa escolher de acôrdo com o assunto quais as comissões que devem opinar, sendo obrigatóris a de Justiça, à exceção do projeto de orçamento e de créditos adicionais.

Os regimentos estabelecem, em geral, o número de comissões que devem falar sốbre as proposições legislativas.

$\mathrm{Na}$ Câmara Federal foi estabelecido que o projeto não pode ser despachado a mais de três comissões admitindo-se com única exceção a do parágrafo primeiro do artigo 50 assim redigido:

$1^{\circ}$ - Quando qualquer Comissão, ou Deputado, pretender que outra Comissão se manifeste sôbre determinada matéria, apresentará requerimento escrito nesse sentido ao Presidente da Câmara, com a indicação obrigatória precisa da questão sôbre a qual deseja o seu pronunciamento. Do despacho do Presidente cabe recurso para o plenário. O pronunciamento da Comissão, no caso do parágrafo anterior versará exclusivamente sôbre a ques- 
tão formulada. Esta limitação regimental nos parece justa, facilitando a tramitação das proposições.

Em cada comissão, o seu Presidente, designa um relator, que dispõe de um prazo fixado pelo Regimento que, é, em geral, de 10 dias.

A Comissão que receber proposição, mensagem ou qualquer outra matéria para exame e parecer, poderá propor a sua adoção ou a sua rejeição, total ou parcial, sugerir o seu arquivamento, formular projetos dêles decorrentes, dar-lhes substitutivos, e apresentar emendas ou subemendas. Entretanto, em se tratando de projetos de lei ou de mensagens de outro Poder não é possível o parecer pelo arquivamento (artigo 40, parágrafo 7 do Regimento da Câmara Federal e artigo 49 do Regimento da A. Legislativa do Estado da Guanabara).

Parece unânime êsse entendimento quanto à competência das comissões, sendo lícito que a comissão concorde com parecer pelo arquivamento de projeto, ou devolução, seja as autor, seja ao Poder Executivo ou Judiciário. O que cabe quanto aos outros Podêres é o pedido de informações e em se tratando de projeto de Deputado é o encaminhamento à Secretaria da Presidência para que sejam preenchidos os requisitos regimentais e não fulminá-lo com parecer contrário sòmente por êsse fundamento, pois seria contrariar o despacho do Presidente que o aceitou.

Na Câmara Federal o assunto foi bem resolvido pelo parágrafo terceiro do artigo 89 assim redigido: A presidência devolverá ao seu autor qualquer proposição, que versar matéria; a) alheia à competência da Câmara; b) evidentemente inconstitucional; c) anti-regimental; e d) com expressão ofensiva a quem quer que seja. Se o autor da proposição, dada ou como inconstitucional, ou como anti-regimental, não se conformar com a decisão, poderá requerer ao Presidente a audiência da Comissão de Justiça, que, se discordar da decisão, restituirá a proposição para o devido exame. É êsse entendimento aceito também pelo Regimento Interno da Assembléia Legislativa da Guanabara em seu artigo 140.

O Regimento deve estabelecer a competência taxativa de cada Comissão técnica, não cabendo a qualquer comissão manifestar-se a) sôbre a inconstitucionalidade de proposição, em contrário ao parecer da Comissão de Justiça; b) sôbre a conveniência, ou a oportunidade de, de despesa, em oposição ao parecer da Comissão de Orçamento; e c) sôbre o que não fôr de sua atribuição especifica, ao apreciar as proposições submetidas a seu exame. O Regimento da Câmara Federal estabelece sanção para quem infringir essa regra, considerando como não escrito o parecer, ou parte dêle, que não respeitar êsses dispositivos regimentais bem como o substitutivo de comissão técnica que não seja competente para opinar sôbre a matéria. 
Os regimentos das casas legislativas devem estabelecer prazos rigidos para as decisões das comissões técnicas bem como para os relatores apresentarem os seus pareceres. Em geral os prazos são de 2 dias para as matérias em regime de urgência, 10 dias as de prioridade e 10 dias nos em regime de tramitação ordinária. $O$ parecer do relator deve ser apresentado na metade dos prazos estabelecidos. Se a Comissão não aceitar o seu parecer designará outro relator, passando o seu a constituir voto em separado.

É principio aceito que qualquer proposição pode, para efeito de estudo, ser subdividida e distribuída a mais de um relator, sendo, obrigatório, porém, a designação de um Relator-Geral, de modo que seja enviado à Mesa um só parecer, que é o da Comissão, pois desaparece a figura do Relator. $\mathrm{O}$ que o plenário discute em qualquer caso é o voto da Comissão e não o de Deputado.

As questões de ordem nas Comissões devem ser resolvidas pelo respectivo presidente, cabendo recurso para o Presidente da casa e para o plenário.

As Comissões Permanentes, dizem os Regimentos da Câmara Federal e da Assembléia Legislativa do Estado da Guanabara, subsistem através das legislaturas. Essa definição é imperfeita, pois, as Comissões Permanentes são criadas no Regimento e se não forem extintas, mediante resolução, o que pode se verificar no início ou no fim de cada legislatura, subsistiram. A melhor doutrina é do Regimento do Senado Federal que não define o que sejam Comissões Permanentes, apenas o seu artigo $62 \mathrm{diz}$ que elas serão constituídas anualmente, no comêço de cada sessão legislativa ordinária e servirão até a instalação da seguinte.

As Comissões Temporárias são as que são constituidas com finalidades especiais, de representação ou de estudo e se extinguem quando cumpriram as suas finalidades.

Na Câmara Federal as Comissões Temporárias são: a) Especiais; b) De Inquérito; c) Externas; e d) Mistas.

As Especiais podem ser constituidas para: I - Dar parecer sôbre emenda constitucional: II - Para dar parecer, após o processamento da representação, sôbre a perda de mandato de Deputado por falta de decôro parlamentar; III - para organizar projeto de lei complementar, ou de código, ou dar-lhes parecer quando em tramitação e IV - para opinar sôbre aplicação de receita vinculada a planos de desenvolvimento regional nos têrmos dos artigos 198 e 199 da Constituição, e artigos $4^{\circ}$ e 29 do Ato das Disposições Transitórias: a) Comissão de Poligono das Sêcas; b) Comissão de Valorização Econômica da Amazônia; c) Comissão da Bacia de São Francisco; e d) Comissão de Mudança da Capital.

A Resolução $\mathrm{n}^{0} 71$, de 1962, da Câmara Federal introduziu algumas modificações importantes no trabalho das comissões ao estatuir no seu artigo 15 o seguinte: poderá ser constituída, me- 
diante requerimento aprovado pelo plenário, Comissão Especial para elaborar projeto de lei ou de código, ou dar-lhe parecer quando em tramitação, opinando sôbre o mérito da proposição. Entretanto, o projeto poderá ser submetido ao plenário a requerimento do Govêrno ou de um décimo dos membros da Câmara. O projeto elaborado na forma dêste artigo será submetido a um só turno de votação global pelo plenário, vedada a apresentação de emendas.

As Comissões Permanentes elegem o seu Presidente e VicePresidente no início da sessão legislativa e as Comissões Temporárias logo que forem constituídas. O Presidente sòmente deve ter voto de qualidade, podendo porém, avocar projeto para relatar. Neste caso deve passar a presidência ao seu substituto legal, para evitar que vote duas vêzes.

A distribuição das matérias nas comissões deve ser feita pelo sistema de sorteio para evitar favoritismo, excluindo de sorteio o autor da proposição.

Esgotados sem parecer os prazos concedidos à Comissão, o Presidente da Câmara, de ofício, ou a requerimento de qualquer Deputado, requisitará o processo e designará um Relator, a quem concederá o prazı para apresentação do parecer que substitua o estudo do órgão técnico em falta. Apresentado êste, passará o processo à Comissão que não tenha falado, ou será mandado a imprimir, caso as outras comissões já tenham se pronunciado (esta prática nos parece salutar, evitando a morosidade dos trabalhos das comissões). 